\title{
Surto Epidemiológico do Vírus do Mosaico Amarelo do Pimentão em Tomateiro na Região Serrana do Espírito Santo
}

\author{
Eunize Maciel-Zambolim¹, Helcio Costaํㄹ Alexandre S. Capucho', Antônio C. de Ávila ${ }^{3}$, Alice K. Inoue- \\ Nagata $^{3}$, \& Elliot W. Kitajima ${ }^{4}$ \\ 'BIOAGRO, CCA., UFV, CEP 36571-000, Viçosa, MG, e-mail: eunize@ufv.br; ${ }^{2}$ INCAPER, CEP 29375-000, Venda Nova do \\ Imigrante, ES; ${ }^{3}$ Embrapa Hortaliças, Cx. Postal 218, CEP 70359-970, Brasília, DF; ${ }^{4}$ Departamento de Entomologia, \\ Fitopatologia e Zoologia Agrícola, ESALQ/USP, CEP 13418-900, Piracicaba, SP
}

(Aceito para publicação em 19/11/2003)

Autor para correspondência: Eunize M. Zambolim

MACIEL-ZAMBOLIM, E., COSTA,H., CAPUCHO, A.S., DE ÁVILA, A.C., INOUE-NAGATA, A.K. \& KITAJIMA, E. W. Surto epidemiológico do vírus do mosaico amarelo do pimentão em tomateiro na região serrana do Espírito Santo. Fitopatologia Brasileira 29:325-327. 2004.

\section{RESUMO}

Este trabalho relata a ocorrência de um surto epidemiológico causado pelo vírus do mosaico amarelo do pimentão (Pepper yellow mosaic virus - PepYMV) em tomateiro (Lycopersicon esculentum) 'Alambra' na região serrana do Estado do Espírito Santo. Os sintomas consistiam de mosaico, definhamento e redução de produção. Visando a caracterização do agente causal foram realizados estudos sorológicos por ELISA, observações ao microscópio eletrônico e determinação da gama parcial de hospedeiros. Ao microscópio eletrônico de transmissão foram observadas, em amostras de tomateiro, partículas alongadas e flexuosas e inclusões cilíndricas típicas de vírus do gênero Potivirus. O PepYMV foi confirmado como agente causal por ELISA indireto. Levantamentos realizados em campos de cultivo demonstraram que a disseminação do vírus é muito rápida. Este é o primeiro relato da ocorrência do PepYMV na cultura do tomate no Brasil, causando sérios danos.

Palavras-chave adicionais: Lycopersicon esculentum, Potyvirus, Pepper yellow mosaic virus.

\section{ABSTRACT}

Outbreak of Pepper yellow mosaic virus in tomatoes in the State of Espírito Santo, Brazil

An outbreak of Pepper yellow mosaic virus (PepYMV) was observed in commercial fields of tomato (Lycopersicon esculentum) 'Alambra' in the Serrana Region of Espírito Santo, Brazil. Symptoms consisted of intense yellow mosaic, weakening of the infected plants and reduction of the yield. The virus was identified by host range, electron microscopy and indirect ELISA. Field surveys indicated a rapid spread of the virus. This is the first report of natural infection of tomato by PepYMV causing severe damage to this crop in Brazil.
O cultivo do tomateiro (Lycopersicon esculentum Mill) é a principal atividade olerícola entre os meses de outubro a março nos municípios de Venda Nova do Imigrante e Domingos Martins, região serrana do Estado do Espírito Santo. O principal híbrido atualmente plantado é o 'Alambra', que representa $70 \%$ da área total cultivada, seguido pelos híbridos 'Carmen', 'Thomas'e 'Diana'. Apesar das doenças viróticas constituirem-se em fator limitante para o tomateiro em vários locais do Brasil, na região serrana do Espírito Santo a incidência, até recentemente, se limitava a poucos casos isolados de tospovírus (Helcio Costa, informação pessoal). No início de 2002 foram observados sintomas semelhantes aos de vírus em alguns plantios comerciais de 'Alambra'. Os sintomas consistiam em mosaico intenso (Figura 1 A,B), definhamento da planta e redução da produção. Os folíolos de algumas plantas apresentavam áreas necróticas na face inferior. Em algumas lavouras as perdas foram totais. Amostras foram coletadas e analisadas na Universidade Federal de Viçosa e Embrapa Hortaliças, onde foram submetidas a testes sorológicos e biológicos para a identificação do agente causal. As amostras de tomateiros com sintomas característicos da virose foram testadas por: ELISA indireta para o Cucumber mosaic virus (CMV) família Bromoviridae, gênero Cucumovirus, Potato virus $Y$ (PVY), Tobacco etch virus (TEV), Pepper yellow mosaic virus (PepYMV- isolado de pimenta malagueta, UFV, fornecido por M.G. Carvalho) família Potiviridae, gênero Potyvirus, Tomato mosaic virus (ToMV) gênero Tobamovirus, e em ELISA direta para o Tomato spotted wilt virus (TSWV), família Bunyaviridae, gênero Tospovirus, Groundnut ring spot virus (GRSV) família Bunyaviridae, gênero Tospovirus, Potato virus X(PVX) e PepYMV [isolado de pimentão (Capsicum annuum L.) - Embrapa Hortaliças]. A possibilidade da infecção por vírus do gênero Begomovirus nas amostras foi verificada através de PCR utilizando oligonucleotídeos gênero específicos localizados no componente A (Rojas et al., 1993).

O PepYMV foi recentemente isolado e caracterizado por pesquisadores da Embrapa Hortaliças como uma nova espécie do gênero Potyvirus de ocorrência natural em pimentão (Inoue-Nagata et al, 2002) e tomate (Cunha et al., 2001, Cunha et al., 2002), provocando severas perdas econômicos nas regiões Centro-Oeste e Sudeste, notadamente em pimentão. $\mathrm{O}$ vírus presente nas amostras reagiu com ambos 

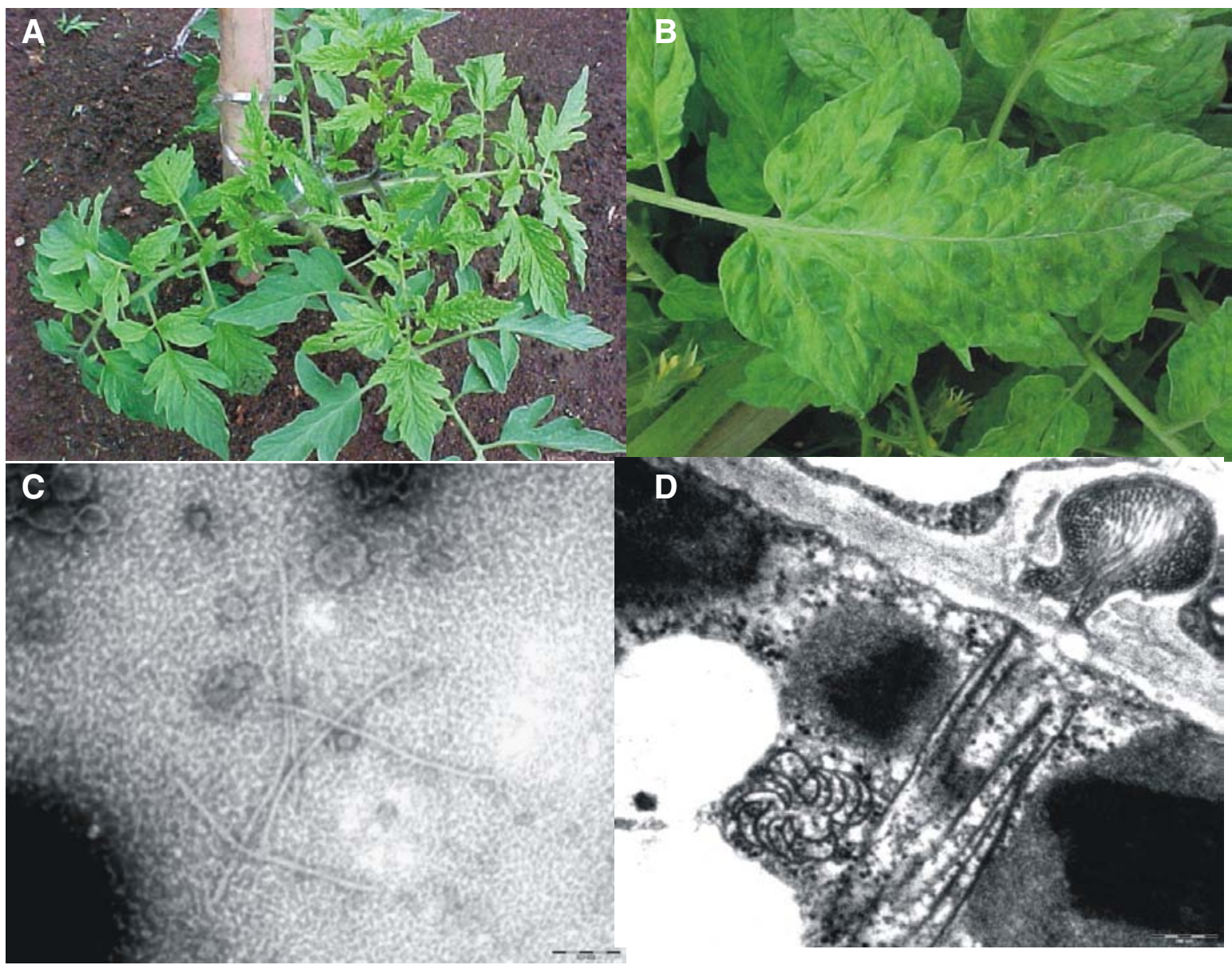

FIG. 1- Pepper yellow mosaic virus - isolado de tomate (Lycopersicon esculentum). A e B) Sintomas de mosaico amarelo intenso no híbrido Alambra. C) Micrografia eletrônica de transmissão de partículas observadas no extrato foliar de tomateiro 'Alambra'. D) Seção ultrafina de tomateiro 'Alambra' com sintomas de mosaico amarelo, mostrando inclusões cilíndricas do tipo catavento (seta) no citoplasma. Um grupo de presumíveis vírions (cabeça de seta) encontra-se junto à parede celular.

anti-soros produzidos contra isolados de PepYMV. Para todos os demais vírus testados os resultados foram negativos. Exames ao microscópio eletrônico de transmissão de amostras coletadas no campo de tomateiro 'Alambra', revelaram a presença de partículas alongadas e flexuosas de aproximadamente 13 por $750 \mathrm{~nm}$ (Figura 1 C) e inclusões cilíndricas (Figura 1 D), típicas do gênero Potyvirus. Extrato foliar de tomateiro com sintoma foi inoculado em $C$. anпиит 'CA212', 'Magali R' e 'Ikeda', Chenopodium amaranticolor Coste \& Reyn, C. quinoa Willd., Cucurbita pepo L. 'Caserta', Datura stramonium L., Gomphrena globosa L., L. esculentum Mill. cv. 'Rutgers' e 'Miller Early Pak', Nicotiana benthamiana L., $N$. glutinosa L., $N$. clevelandii Gray, $N$. debney Domin, N. tabacum L. 'Havana 425' e 'Samsun' e Nicandra physaloide (L.) Gaertn. O vírus causou mosaico amarelo em folhas de tomateiro 'Rutgers', semelhante ao sintoma observado em 'Alambra'. Em tomateiro 'Miller Early Pak' foi verificada a presença de manchas necróticas escuras nas margens das folhas inoculadas. Em pimentão, apesar da 'CA 212' não mostrar sintomas, na 'Ikeda' observou-se mosaico. O vírus causou mosaico amarelo forte com formação de bolhas, deformação foliar e redução de crescimento em $N$. benthamiana, clareamento de nervuras em $N$. glutinosa, mosqueado em $N$. debney e mosaico severo e rugosidade das folhas em $N$. physaloides. As demais plantas inoculadas não apresentaram sintomas visuais. Não foram realizados testes sorológicos.

Dois levantamentos com intervalos de dez dias realizados em sete campos comerciais de tomate, onde foram inspecionadas visualmente todas as plantas de 'Alambra' e 'Carmen' demonstraram a presença de sintomas, indicando uma rápida disseminação do PepYMV principalmente em 'Alambra' (Tabela 1). Oitenta e oito amostras, provenientes de várias áreas de cultivo da região, apresentando mosaico, foram analisadas mediante ELISA indireto. Os resultados do teste mostraram que o vírus contido nas amostras reagiu fortemente com o anti-soro contra o PepYMV-UFV (Tabela 1).

Dado ao seu grande potencial destrutivo no tomateiro, faz-se urgente o seu monitoramento em outras regiões produtoras de tomate no Brasil assim como buscar por fontes de resistência em tomateiro.

Os isolados de PepYMV de tomateiro descritos até 
TABELA 1 - Análise da percentagem de infecção, sintomatologia e sorologia em amostras de tomate (Lycopersicon esculentum) coletadas em plantios comerciais na região serrana do Espírito Santo

\begin{tabular}{|c|c|c|c|c|c|c|}
\hline \multirow{2}{*}{$\begin{array}{l}\text { Espécie Vegetal / Local } \\
\text { Tomate (Lycopersicon esculentum) 'Alambra' }\end{array}$} & \multirow[t]{2}{*}{$\begin{array}{c}\text { Quantidade } \\
\text { de pés } \\
\text { plantados }\end{array}$} & \multicolumn{2}{|c|}{$\begin{array}{l}\text { \% de infecção } \\
\text { levantamentos }{ }^{1}\end{array}$} & \multirow[t]{2}{*}{$\begin{array}{c}\text { No. de } \\
\text { plantas } \\
\text { testadas }^{2} \\
\end{array}$} & \multirow[t]{2}{*}{ Sintoma $^{3}$} & \multirow[t]{2}{*}{$\begin{array}{c}\text { Resultado } \\
\text { ELISA }^{4}\end{array}$} \\
\hline & & & & & & \\
\hline local: Caxixe-Venda Nova do Imigrante & 10.000 & 70 & 99 & 20 & MI & + \\
\hline Córrego Alto Vargem Alta & 2.300 & 0,4 & 70 & 8 & MI & + \\
\hline Córrego da Prata Vargem Alta & 3.000 & 35 & 90 & 10 & MI & + \\
\hline Caxixe Venda Nova do Imigrante & 5.000 & 1 & 80 & 15 & MI & + \\
\hline Caxixe Venda Nova do Imigrante & 3.200 & 1 & 70 & 10 & MI & + \\
\hline Caxixe Venda Nova do Imigrante & 1.500 & 0,5 & 70 & 8 & MI & + \\
\hline \multicolumn{7}{|l|}{ Tomate 'Carmen' } \\
\hline local: São Paulinho de Arace-Domingos Martin & 5.000 & 0,8 & 40 & 15 & MI & + \\
\hline Córrego Alto Vargem Alta & 2.500 & 0,7 & 20 & 10 & $\mathrm{MB}$ & + \\
\hline Nicotiana benthamiana infetada com PepYMV 5 & - & - & - & - & MI & + \\
\hline Nicotiana benthamiana sadia & - & - & - & - & - & - \\
\hline Tomate Rutgers infetado ${ }^{5}$ & - & - & - & - & $\mathrm{MI}$ & + \\
\hline Tomate Rutgers sadio & - & - & - & - & - & - \\
\hline $\begin{array}{l}\text { levantamentos visuais efetuados nos dias 30/10/02 e 10/11/ } \\
\text { testadas por ELISA } \\
\text { MI - mosaico intenso; MB - mosaico brando; (-) sem sinto } \\
\text { positivo (+) e negativo (-). } \\
\text { infecção experimental. }\end{array}$ & espectivamente. & & & & & \\
\hline
\end{tabular}

então causavam sintomas brandos em tomateiro, quando comparados a sintomas causados em pimentão (Cunha et al., 2002). Este é um problema em potencial não só para o cultivo do tomateiro como também para o pimentão na região serrana do Espírito Santo e requer urgente pesquisa em resistência varietal para enfrentá-lo.

\section{REFERÊNCIAS BIBLIOGRÁFICAS}

CUNHA, L.C.V., NAGATA, T., RESENDE, R.O. \& INOUENAGATA, A.K. Biological, serological and genomic characteristics of a potyvirus isolated from tomato in Brazil. Virus Reviews \& Research 6:154-155. 2001.

CUNHA, L.C.V., NAGATA, T., RESENDE, R.O. \& INOUE-
NAGATA, A.K. Characterization of Brazilian potyvirus isolates from tomato and swetpepper. Virus Reviews \& Research 7:148. 2002.

DELLAPORTA, S.L., WOOD, J. \& HICKS, J.B. A plant DNA minipreparation: Version II. Plant Molecular Biology Reporter 1:1921. 1983.

INOUE-NAGATA, A.K., FONSECA, M.E.N., RESENDE, R.O., BOITEUX, L.S., MONTE, D.C., DUSI, A.N., ÁVILA, A.C. \& VAN DER VLUGT, R.A.A. Pepper yellow mosaic virus, a new potyvirus in sweet pepper Capsicum annuum. Archives of Virology 147:849855. 2002.

ROJAS, M.R., GILBERTSON R.L., RUSSELL, D.R. \& MAXWELL, D.P. Use of degenerate primers in the polymerase chain reaction to detect whitefly-transmitted geminivirus. Plant Disease 77:340-347. 1993. 